\title{
Educação ambiental e meio ambiente: \\ As práticas pedagógicas dos professores da educação básica de Palmas - TO
}

\author{
Berenice Feitosa da Costa Aires ${ }^{1}$ \\ Rogério Pereira de Bastos $^{2}$
}

\begin{abstract}
RESUMO: Investigam-se como as representações sociais sobre Meio Ambiente (MA) e Educação Ambiental (EA) de 71 professores de 15 escolas da educação básica da cidade de Palmas (TO), estão orientando suas praticas pedagógicas no Ensino Fundamental e Médio, nas três redes de ensino: privada, municipal e estadual. Buscando-se uma generalização para as práticas de $E A$, foi testado se a freqüência das respostas dos questionários podia ser explicada pela rede de ensino, utilizando-se o teste Qui-Quadrado e o Teste Exato de Fischer. Os resultados indicam que as representações de EA e MA dos professores orientam suas práticas pedagógicas e essas não diferem entre as três redes de ensino.
\end{abstract}

Palavras-chave: meio ambiente; educação ambiental; práticas pedagógicas.

\section{INTRODUÇÃO}

A abordagem da problemática ambiental, intensificada na era industrial, ganha repercussão mundial a partir da Conferência das Nações Unidas sobre Meio Ambiente realizada em Estocolmo, na Suécia em 1972. Essa problemática é decorrente de um longo processo histórico evidenciado pelas rápidas transformações que afetam a humanidade e a vida no planeta, e tem no advento da Revolução industrial e no avanço do capitalismo as bases de seu crescimento, cujo ápice ocorreu no século XX. A partir da Revolução industrial e do processo de urbanização do mundo começaram a surgir os sinais de que a exploração dos recursos naturais para atender as necessidades humanas impactava o meio ambiente e se constituía em problemas ambientais. Desde então se intensifica e desencadeia inúmeros movimentos ambientalistas no mundo para discutir a questão ambiental.

Em todas as discussões ocorridas no sentido de recuperar, minimizar ou preservar a fonte de recursos, a educação foi apontada como pilar central das estratégias de promoção dos valores e comportamentos sociais de modo que fosse garantido um desenvolvimento harmônico com a natureza, baseado no princípio da racionalidade, da solidariedade, da responsabilidade, da cooperação e da participação.

Assim, a EA ganha proporção no sentido de ser uma das balizadoras para equacionar esses dilemas, principalmente através da educação formal. Nesse sentido é importante que a prática pedagógica seja criativa e democrática, fundamentada no diálogo que, segundo Freire (1995), aparece como condição para o conhecimento. Porque o ato de conhecer acontece no processo social, do qual o dialogo é a mediação. Nessa perspectiva pedagógica, o ser humano é concebido como um ser aberto e essencialmente comunicativo, sendo que seu processo como ser só é possível no diálogo.

A teoria das representações sociais tem sido utilizada para o estudo de muitas questões contemporâneas por diversos pesquisadores, que compreendem que os pontos

1 Professora da Universidade Federal do Tocantins. UFT. E Doutoranda em Ciências Ambientais-UFG. Email: <berenice@uft.edu.br >.

2 Professor do Programa de Pós-graduação em Ciências Ambientais e Ecologia- UFG. Email: <bastos@icb.ufg.br> Revbea, Rio Grande, 6: 52-61, 2011. 
comuns entre elas são a influências recebidas dos conhecimentos tradicionais, étnicos, populares e científicos, ou seja: elas são visões especificas de mundo e senso comum que diferentes indivíduos e grupos sociais possuem, de forma fragmentada e difusa (REIGOTTA, 1999). No que diz respeito à contemporaneidade dos conhecimentos relacionados ao meio ambiente, verifica-se que se encontra em plena construção, não existindo o consenso sobre esse termo nem mesmo na comunidade cientifica. Admitindo-se que o mesmo ocorra com a comunidade em geral, é evidente a necessidade de conhecer e trabalhar a partir das representações que as pessoas envolvidas no processo educativo têm a respeito da temática (BRASIL, 2001; REIGOTA, 2001).Assim sendo, não há dúvidas de que uma busca sobre representações de MA e EA poderá auxiliar na identificação de um numero elevado de discursos, conceitos, vivências e práticas nas mais diversas áreas de conhecimento. Assim como Reigota (1998), entendemos que, a partir das representações de MA e EA dos professores (as), é possível caracterizar suas práticas pedagógicas.

Desta forma, o objetivo deste estudo foi: investigar como as representações sociais sobre Meio Ambiente e Educação Ambiental de professores da educação básica da cidade de Palmas (TO), estão orientando suas praticas pedagógicas cotidianas relacionadas à Educação Ambiental no Ensino Fundamental e Médio, nas três redes de ensino: privada, municipal e estadual.

\section{PROCEDIMENTOS METODOLÓGICOS}

A metodologia utilizada na investigação foi a pesquisa de campo e analise documental. Em campo, inicialmente buscamos estabelecer uma aproximação com as diretoras, coordenadoras e professoras, consolidando uma relação de respeito e apresentando as intenções da pesquisa. As técnicas de coletas de dados foram: observações, análise documental e aplicação de questionários.

As observações auxiliaram na caracterização do ambiente escolar. Através da análise documental fez o estudo dos planejamentos pedagógicos das escolas e planejamento individual de cada professor investigado. Os questionários com questões abertas e fechadas proporcionaram aos professores investigados uma projeção das representações sociais que eles possuem em relação ao MA e EA nas suas práticas pedagógicas. Do ponto de vista operacional foram selecionados 25 professores da rede estadual, 23 professores da rede municipal e 23 professores da rede privada de ensino.

O questionário composto de 15 questões identificou qual o conhecimento os professores tinham sobre os documentos oficias de EA, os temas transversais, os temas ambientais mais trabalhados nas suas disciplinas, metodologias utilizadas para a inclusão do tema Meio Ambiente, e qual a concepção de EA utilizavam em suas práticas cotidianas de Educação Ambiental.

As análises estatísticas foram utilizadas para determinar se as freqüências dos eventos observados entre as redes de ensino a qual os professores estão vinculados diferem daquela que poderia ser explicada pelo simples acaso. Foi utilizado o Teste Quiquadrado e quando os pressupostos deste teste foram violados (freqüência esperadas menores que 1 ou $25 \%$ delas menores que 5) foi aplicado o teste exato de Fischer.

\section{RESULTADOS E DISCUSSÕES}

Em relação aos documentos referentes a educação ambiental, Parâmetros Curriculares Nacionais PCNs e a Agenda 21 foram os mais citados pelos professores (Tabela 1), sendo que as diferenças na freqüência de citação destes documentos entre as Redes Municipal, Estadual e Privada não difere daquela esperada pelo acaso (Tabela 1). Assim sendo, cabe fazer um destaque maior com relação aos PCNs e a implantação da

Revbea, Rio Grande, 6: 52-61, 2011. 
EA no âmbito formal. A partir de 1995 o governo brasileiro elaborou os (PCNs), tratando o tema Meio Ambiente de forma transversal, pelo entendimento de que a transversalidade perpassa por todo o campo do conhecimento e, como muitas escolas já realizam atividades voltadas à questão ambiental, essa inclusão propicia a discussão e a busca de soluções, independente da área de conhecimento.

Neste direcionamento a EA apresenta-se também transversal, implicando na contribuição com a construção da cidadania dos professores, diferenciando-se da educação tradicional. Mas tendo que enfrentar todas as heranças desta educação tradicional.

"Ao diferenciar-se da educação tradicional e apresentar-se como saber transversal, a EA inova, mas também arca com as dificuldades de sua assimilação pela educação formal, estruturada disciplinarmente. Como conseqüência resulta que, a despeito do interesse que parece despertar nas escolas e professores, toda atividade de EA no ensino formal tem se dado através de projetos pontuais e extracurriculares." (CARVALHO, 2002, p.164).

Em conformidade com os Parâmetros Curriculares Nacionais, o sistema de ensino público e privado de Palmas incluiu nas suas propostas curriculares os temas transversais definidos por este referencial. Todavia, isto não significa que todos estes temas tenham recebido atenção pedagógica por parte dos profissionais da educação, até porque existe uma lacuna entre a formação inicial do professor e a prática metodológica da transversalidade.

Outro documento importante para orientar a prática na educação ambiental é a Agenda 21, a qual foi formulada pela Sociedade Civil na Conferencia da Organização das Nações Unidas sobre MA e Desenvolvimento no Rio de Janeiro em 1992, durante o Fórum Global das ONGs. Esse tratado apresenta em seus princípios que EA deve envolver uma perspectiva holística e sistêmica, enfocando a relação entre o ser humano, a natureza e o universo de forma interdisciplinar, valorizando as diversas formas de conhecimento em um processo permanente de aprendizagem. Devem integrar conhecimentos, aptidões, valores, atitudes, ações, ajudando a desenvolver uma consciência ética sobre todas as formas de vida.

Percebemos que tanto as escolas como os professores têm conhecimento sobre a Agenda 21. No entanto, nenhuma das escolas investigadas estabeleceu como meta a implantação destes programas, cujo propósito é contribuir com o planejamento e enraizamento da EA nas unidades escolares.

Outro documento muito importante é o Programa Nacional de Educação Ambiental (PRONEA), que regulamenta a Lei da Política Nacional de Educação Ambiental, Lei $n$ 9.795 de 27/04//1999. Segundo essa lei, EA formal deverá ser desenvolvida como uma prática educativa integrada, contínua e permanente em todos os níveis e modalidades do ensino formal. Apesar da importância deste documento para EA, no geral um documento pouco conhecido pelos professores, sendo que $24,0 \%$ dos professores da Rede Estadual e respectivamente $17,4 \%$ dos professores da Rede Municipal e Privada citaram este documento. As diferenças entre as redes de ensino na freqüência de citação deste documento não são diferente da esperada pelo acaso (Tabela 1).

A Declaração de Tbilisi foi o documento que apresentou a menor freqüência de citação pelos professores apesar de ter sido publicada aproximadamente na mesma época que a Declaração de Estocolmo (Tabela 1). Os documentos contextualizados para o estado do Tocantins (PCTO e Carta do Lago de Palmas) também apresentaram uma baixa freqüência de citação por parte dos professores, não existindo nenhuma relação da freqüência de citação destes documentos com a rede que o professor pertence (Tabela 1).

Revbea, Rio Grande, 6: 52-61, 2011. 
Tabela 1: Freqüência de citação dos documentos oficiais em EA pelos professores das Redes

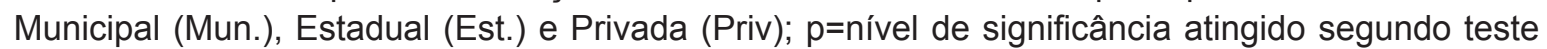
exato de Fisher, $\mathrm{N}=$ número de professores que responderam a questão.

\begin{tabular}{|c|c|c|c|c|c|c|}
\hline Deconentes & $\mathbf{M}$ & $\begin{array}{l}\text { Lst } \\
\text { (\%) }\end{array}$ & $\begin{array}{l}\text { Priv } \\
(\%)\end{array}$ & $\underset{\mathbf{M} \leq \mathbf{f})}{\mathbf{P}} \mathrm{X}$ & $\underset{\text { Priv) }}{\mathbf{P}} x$ & $\begin{array}{c}\text { P } \\
\text { (RstX } \\
\text { Priv) }\end{array}$ \\
\hline FCN & 78,3 & 88,0 & 88,0 & 0,30 & 0,37 & $\mathbf{0 , 1 1}$ \\
\hline Agenda 21 & 65,2 & 68,0 & 56,5 & 0,84 & 0,38 & 0,30 \\
\hline $\begin{array}{l}\text { Dedarapie de } \\
\text { Estucelleve }\end{array}$ & 30,4 & 48,0 & 43,5 & 0,21 & 0,27 & 0,49 \\
\hline Canta dage lage & 43,5 & 24,0 & 47,8 & 0,13 & 0,50 & 0,07 \\
\hline FCTO & 26,1 & 40,0 & 26,1 & 0,24 & 0,63 & 0,24 \\
\hline $\begin{array}{l}\text { Lei Federal } \\
\text { 979569 }\end{array}$ & 17,4 & 24,0 & 17,4 & 0,42 & 0,65 & 0,42 \\
\hline $\begin{array}{l}\text { Dedhraciea de } \\
\text { Tbrisi }\end{array}$ & 4,4 & 8,0 & 8,7 & 0,53 & 0,50 & 0,66 \\
\hline $\mathbf{N}$ & 23 & 25 & 23 & & & \\
\hline
\end{tabular}

Em relação aos temas transversais abordados pelos professores o tema transversal Meio Ambiente é o que apresentou a maior freqüência de citação (Tabela 2) e os professores da Rede Municipal citaram mais do que os professores da Rede Estadual. Todavia, a freqüência de citação deste tema pelos professores da Rede Privada não difere da esperada pelo acaso em relação aos professores da Rede Municipal e aqueles da Estadual (Tabela 2). A freqüência de citação dos outros temas transversais (Orientação Sexual, Pluralidade Cultural, Trabalho/Consumo e Ética) pelos professores das três redes de ensino não difere daquela esperada pelo acaso. Em destaque, está o tema transversal Saúde que foi mais citado pelos professores da Rede Municipal do que da Rede Estadual. Todavia, a freqüência de citação deste tema pelos professores da Rede Privada em relação aos da Rede Estadual e Municipal não difere daquela esperada pelo acaso (Tabela 2). 
Tabela 2: Freqüência de citação dos Temas transversais abordados pelos professores das

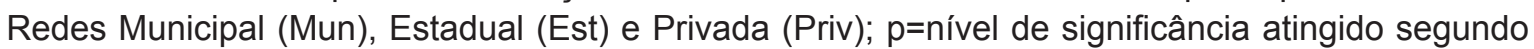
teste exato de Fisher, *valores significativos a $0,05, \mathrm{~N}=$ número de professores que responderam a questão.

\begin{tabular}{|c|c|c|c|c|c|c|}
\hline $\begin{array}{l}\text { Temas } \\
\text { transversais }\end{array}$ & ME & $\begin{array}{l}\text { Est } \\
(\%)\end{array}$ & $\begin{array}{l}\text { Priv } \\
(\%)\end{array}$ & $\underset{\mathbf{L}=\mathbf{A})}{\mathrm{P}} \mathrm{X}$ & $\underset{\text { Priv) }}{\mathbf{P}} \mathbf{X}$ & $\begin{array}{c}\text { P } \\
\text { (Xst X } \\
\text { Priv) }\end{array}$ \\
\hline Mei Ambiemte & 100,0 & 76,0 & 91,3 & $* 0,01$ & 0,24 & 0,15 \\
\hline Saúde & 69,6 & 32,0 & 52,2 & $\begin{array}{c}*<0,01 \\
11\end{array}$ & 0,18 & 0,13 \\
\hline $\begin{array}{l}\text { Oriembycion } \\
\text { serinl }\end{array}$ & 36,1 & 36,0 & 21,7 & 0,52 & 0,17 & 0,22 \\
\hline Ética & 69,6 & 48,0 & 43,5 & 0,11 & 0,06 & 0,49 \\
\hline TraballadConsid & 47,8 & 28,0 & 52,2 & 0,13 & 0,50 & 0,08 \\
\hline $\begin{array}{l}\text { Furaldade } \\
\text { Cultural }\end{array}$ & 56,5 & 56,0 & 52,2 & 0,60 & 0,50 & 0,51 \\
\hline $\mathbf{N}$ & 23 & 25 & 23 & & & \\
\hline
\end{tabular}

O tema MA apresenta-se conjuntamente com outros temas a serem trabalhados transversalmente: ética, pluralidade cultural, saúde e orientação sexual. Com relação a esse conjunto, Tristão (2004) aponta que é mais uma tentativa de viabilizar a interdisciplinaridade que a transversalidade, pois acredita que

"[...] possuem abordagens distintas. Inicia-se aqui, uma compartimentalização. Ora a educação ambiental abrange tanto a dimensão ética quanto a pluralidade cultural que é balizadora dos próprios princípios da educação ambiental." (TRISTÃO, 2004, p. 51).

Entendemos que este caráter transversal e interdisciplinar da Educação Ambiental ainda é um desafio para os professores, que acabam diversificando experiências de toda natureza na tentativa de fazer a transversalidade do tema MA. Mas é exatamente nesta diversidade de experiências que está a riqueza da Educação Ambiental, que apresenta uma amplidão de possibilidades de educação e reeducação do cidadão de modo que ele possa compreender o mundo a sua volta e posicionar-se diante dele de forma responsável.

Buscando conhecer a interdisciplinaridade da EA, pedimos que os professores revelassem como se dá a inclusão do tema MA em sua disciplinas. As metodologias mais citadas são aquelas mais tradicionais como a realização de pesquisas em jornais, revistas, a produção de materiais textuais, desenhos e cartazes, a exploração de conteúdos das disciplinas que ministram e a abordagem de problemas da comunidade (Tabela 3). As diferenças na freqüência de citação destas metodologias entre os professores das Redes Municipal, Estadual e Privada não diferiu daquela esperada pelo acaso (Tabela 3). O desenvolvimento de atividades em áreas verdes, a realização de palestras e o desenvolvimento de projetos com entidades parceiras foram os métodos menos citados pelos professores não existindo diferenças entre as três redes de ensino na freqüência de citação destas metodologias (Tabela 3).

Uma abordagem interdisciplinar foi mais freqüentemente citada pelos professores da Rede Privada quando comparado aos professores da Rede Estadual (Tabela 3), sendo que a freqüência desta abordagem não difere entre os professores da Rede privada quando comparados a Rede municipal e destes quando comparados a Rede Estadual. 
Tabela 3: Freqüência de citação das metodologias utilizadas para a inclusão do Tema Transversal Meio Ambiente pelos professores das Redes Municipal (Mun), Estadual (Est) e Privada (Priv); $p=$ nível de significância atingido segundo teste exato de Fisher, *valores significativos a 0,05, $\mathrm{N}=$ número de professores que responderam a questão.

\begin{tabular}{|c|c|c|c|c|c|c|}
\hline Meted-ragin & (\%) & $\begin{array}{l}\text { Lst } \\
\text { (\%) }\end{array}$ & $\begin{array}{l}\text { Priv } \\
(\%)\end{array}$ & $\underset{\mathbf{L s})}{\mathrm{P}} \mathrm{X}$ & $\underset{P\left(\operatorname{miv}^{-} \mathrm{X}\right.}{\mathrm{P}}$ & $\begin{array}{c}\text { P } \\
\text { (Xst X } \\
\text { Priv) }\end{array}$ \\
\hline Pesqisos & 78,3 & 78,9 & 66,7 & 0,63 & 0,30 & $\mathbf{0 , 3 1}$ \\
\hline $\begin{array}{l}\text { Predecie de } \\
\text { nteriais }\end{array}$ & 82,6 & 63,2 & 71,4 & 0,14 & 0,30 & 0,41 \\
\hline $\begin{array}{l}\text { Rrpesipipe de } \\
\text { comteides }\end{array}$ & 82,6 & 63,2 & 71,4 & 0,14 & 0,30 & 0,42 \\
\hline $\begin{array}{l}\text { Problemas da } \\
\text { comonidade }\end{array}$ & 60,9 & 52,6 & 33,3 & 0,41 & 0,06 & 0,18 \\
\hline Palestirs & 17,4 & 42,1 & 15,0 & 0,07 & 0,58 & 0,06 \\
\hline Projetes & 34,8 & 31,6 & 10,0 & 0,54 & 0,06 & 0,10 \\
\hline $\begin{array}{l}\text { Interdisiplima } \\
\text { r }\end{array}$ & 73,9 & 63,2 & 90,0 & 0,34 & 0,17 & $* 0,05$ \\
\hline $\begin{array}{l}\text { Atividades } \\
\text { áneas verdes }\end{array}$ & 17,4 & 42,1 & 25,0 & 0,07 & 0,40 & 0,21 \\
\hline $\mathbf{N}$ & 23 & 19 & 21 & & & \\
\hline
\end{tabular}

Em relação aos temas ambientais mais trabalhados nas suas disciplinas, os temas água, desmatamento, queimadas, lixo, poluição do ar/ar, e flora/solo foram os mais freqüentemente citados pelos professores (Tabela 4) sendo que as diferenças na freqüência de citação dos temas desmatamento, queimada, lixo e flora/solo entre as três redes de ensino não diferem daquela esperada pelo acaso. Por outro lado, o tema água foi mais citado pelos professores da Rede municipal do que pelos professores da Rede Estadual (Tabela 4) e o tema poluição do ar/ar são mais citados pelos professores da Rede Municipal quando comparados as outras duas redes de ensino (Tabela 4). Os temas poluição sonora/ visual, agrotóxico e caça foram os temas menos citados pelos professores, sendo que as diferenças na freqüência de citação destes temas entre as três redes não difere daquela esperada pelo acaso (Tabela 4). Os temas ambientais voltados para uma abordagem social, como cidadania, higiene/nutrição também foram citados com uma grande freqüência pelos professores e as diferenças na freqüência de citação entre as redes não difere daquela esperada pelo acaso (Tabela 4). 
Tabela 4: Freqüência de citação dos temas ambientais mais abordados pelos professores das Redes Municipal (Mun), Estadual (Est) e Privada (Priv); $p=$ nível de significância atingido segundo teste exato de Fisher, ${ }^{*}$ valores significativos a $0,05, \mathrm{~N}=$ =número de professores que responderam a questão.

\begin{tabular}{|c|c|c|c|c|c|c|}
\hline $\begin{array}{l}\text { Tems } \\
\text { ambiemtais }\end{array}$ & $\begin{array}{l}M \\
(\%)\end{array}$ & $\begin{array}{l}\text { Est } \\
\text { (\%) }\end{array}$ & $\begin{array}{l}\text { Priv } \\
(\%)\end{array}$ & $\underset{\mathbf{E s t}}{P} x$ & $\underset{\text { Priv) }}{\mathbf{P}}$ & $\begin{array}{c}\mathbf{P} \\
\text { (KstX } \\
\text { Priv) }\end{array}$ \\
\hline$A_{g}=$ & 100,0 & 79,2 & 90,0 & $+0,03$ & 0,21 & 0,29 \\
\hline Des:matamente & 87,0 & 75,0 & 75,0 & 0,25 & 0,27 & 0,64 \\
\hline Qneimadas & 87,0 & 75,0 & 65,0 & 0,25 & 0,09 & 0,35 \\
\hline Lino & 95,7 & 79,2 & 80,0 & 0,10 & 0,13 & 0,62 \\
\hline Polnipipe atar & 95,7 & 54,2 & 65,0 & $*<0,01$ & $* 0,01$ & 0,34 \\
\hline 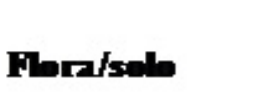 & 65,2 & 50,0 & 55,0 & 0,22 & 0,36 & 0,49 \\
\hline 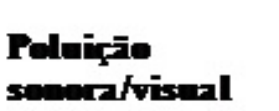 & 52,2 & 45,8 & 55,0 & 0,44 & 0,55 & 0,38 \\
\hline Agratisices & 26,1 & 29,2 & 30,0 & 0,54 & 0,52 & 0,60 \\
\hline Cape & 21,7 & 16,7 & 15,0 & 0,47 & 0,43 & 0,61 \\
\hline Cidadarin & 73,9 & 50,0 & 70,0 & 0,08 & 0,52 & 0,15 \\
\hline $\begin{array}{l}\text { Higiene/Natric } \\
\text { ino }\end{array}$ & 82,6 & 62,5 & 70,0 & $\mathbf{0 , 1 1}$ & 0,27 & 0,42 \\
\hline $\mathbf{N}$ & 23 & 24 & 20 & & & \\
\hline
\end{tabular}

Ao investigarmos com qual das vertentes de Educação Ambiental mais se identificam ao desenvolver atividades de EA, e ao confrontar os documentos dos planejamentos das escolas da rede pública (estadual e municipal) e as Propostas Curriculares das escolas privadas, e ainda a partir da observação. A vertente de EA mais citada pelos professores é aquela na qual são considerados todos os aspectos políticos, sociais, econômicos, culturais, ambientais e históricos, dentro de uma visão integrada. As diferenças nas freqüências de citação entre as redes não difere daquela esperada pelo acaso (Tabela 5). 
Tabela 5: Freqüência de citação da vertente ambiental adotada pelos professores das Redes

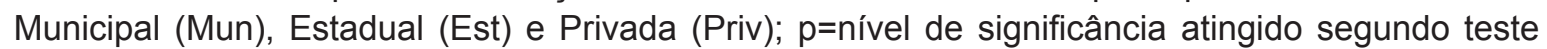
exato de Fisher.

\begin{tabular}{|c|c|c|c|c|c|c|}
\hline $\begin{array}{l}\text { Vertente } \\
\text { ambiental }\end{array}$ & $\frac{M}{(\%)}$ & $\begin{array}{l}\text { Lst } \\
\text { (\%) }\end{array}$ & $\begin{array}{l}\text { Priv } \\
(\%)\end{array}$ & $\underset{\mathbf{M} \leq t)}{\mathrm{P}} \mathrm{X}$ & $\underset{\text { Priv) }}{\mathbf{P}} \mathbf{X}$ & $\begin{array}{c}\text { P } \\
\text { (KstX } \\
\text { Priv) }\end{array}$ \\
\hline Intezrada & 90,0 & 82,6 & 94,4 & 0,40 & 0,54 & 0,26 \\
\hline Arising & 10,0 & 17,4 & 5,6 & & & \\
\hline $\mathbf{N}$ & 20 & 23 & 18 & & & \\
\hline
\end{tabular}

Todavia o que nos aponta a pesquisa é que a EA praticada por esses docentes é evidenciada também por uma concepção de EA como uma educação conscientizadora, promotora da preservação e da conservação do ambiente. Essa idéia de EA enquanto promotora da conservação do ambiente "trata-se daqueles discursos que vêem o homem apenas como fator de alteração do equilíbrio de um meio; daquelas análises que não falam da sociedade mas apenas da ação antrópica" (MORÃES, A. 2002, p.52).

Ainda, identificamos uma prática de EA, em que os professores possuem uma visão de EA que interrelacionam a conservação do ambiente com os sistemas de valores, as relações sociais e as leis, o que nos remetem às palavras de Jacobi (2004, p.31) "o mais desafiador é evitar cair na simplificação da educação ambiental e superar uma relação pouco harmoniosa entre indivíduos e o meio ambiente através de práticas localizadas e pontuais".

Identificamos também uma concepção de EA voltada para o desenvolvimento de uma postura utilitarista em relação à natureza. Essa postura reforça a visão antropocêntrica, em que o MA é fonte de recursos naturais, disponíveis para o sustento do ser humano.

As vertentes de EA identificadas acima encontram-se inseridas numa dimensão física, o que segundo Carvalho (2005), é classificada como Tipologia de EA com predomínio de ciências que se caracteriza como aquisição de conhecimentos sobre os elementos naturais; e como prática conscientizadora que tem como característica a preservação da natureza através de ações comportamentalistas; e como desenvolvimento de uma postura utilitarista que entende o MA como fonte de recursos.

Notamos que é comum a representação de EA enquanto disciplina no fazer pedagógico, no cotidiano escolar. Essa assertiva pode ser fundamentada tanto pela falta de conhecimento mais aprofundado sobre a incorporação da EA no ensino formal, quanto pela forma como tem sido repassado para a escola o fazer pedagógico na $E A$, ou ainda pela visão fragmentada e reducionista presente no sistema educacional. Essa visão fragmentada e reducionista encontra-se inserida no "paradigma da disjunção" proposto por Morin (2000, p.41):

"[...] a hiperespecialização impede tanto a percepção do global (que ela fragmenta em parcelas), quanto do essencial (que ela dissolve). Impede até mesmo tratar corretamente os problemas particulares, que só podem ser propostos e pensados em seu contexto. [...] a cultura científica e técnica disciplinar parcela, desune e compartimenta os saberes, tornando cada vez mais difícil sua contextualização. [...] o recorte das disciplinas impossibilita apreender "o que está sendo tecido junto."

Utilizando as tipologias de EA de Carvalho (2005), as representações acima se inserem numa dimensão complexo-interativa que apresenta uma prática baseada numa educação 
para a construção de um ambiente agradável, como educação a partir do cotidiano, e como prática conscientizadora e de transformação humana.

Nesse sentido, embora a grande maioria dos professores tenha assinalado que a EA praticada por eles se identifica com uma vertente em que são considerados todos os aspectos políticos, sociais, econômicos, culturais, ambientais e históricos, dentro de uma visão integrada, o que aponta a pesquisa é que todas as vertentes de EA são praticadas pelos professores, não elegendo qual é certa ou errada, porque o erro é parte integrante do processo e faz parte do aprendizado, mas circunscreve-se na tentativa de visualização dessas diferenças e, sobretudo, no direcionamento de superação dos conflitos e limites da EA.

A partir dessas representações, observamos que as diversas concepções que foram constatadas ora divergências, ora aspectos similares, o que nos leva a concluir que a tendência da formação destas relaciona-se com a vivência de cada um, e com a experiência profissional. $E$ também fica evidente que a forma como os professores (as) tanto da rede pública (municipal e estadual) e da rede privada percebem e representam o MA, está direcionando suas prática pedagógicas em EA.

\section{CONSIDERAÇÕES FINAIS}

Os resultados da pesquisa indicam que os professores (as) da Educação de Palmas (TO), em suas práticas, buscam incorporar a temática ambiental, baseada nas suas concepções de MA, que acabam por constituir-se em sua vivencia de EA.

Para nós, a questão central é tomar todas as representações possíveis de acréscimos, de debates, trabalhando com o similar, com o significado que o ambiente tem para cada um, cada uma, respeitando as diferenças, porem não incorrendo no erro de aceitar o plural sem confrontar as interfaces deste.

Como perspectiva em EA, é interessante convidarmos as escolas a entrelaçar os fios que a tecem, percorrendo caminhos e rotas em busca de sua consolidação, de novas formas de compreender o mundo, imbuídos do que nos aponta Freire (1987) com relação ao significado dado à práxis: [...] "é reflexão e ação dos homens sobre o mundo para transformá-lo."

Entendemos que a Educação Básica de Palmas, tanto a rede pública, quanto a privada, precisa incorporar uma Educação Ambiental tecida pela prática reflexiva, que significa questionar as relações que existem entre as coisas, buscar o sentido, questionar o fazer pedagógico, para a partir daí começar a mudar as concepções. É preciso perceber as diferenças epistemológicas, os esquemas conceituais, para compreender os processos.

\section{REFERÊNCIAS}

BRASIL. Secretaria de Educação Fundamental. Parâmetros curriculares nacionais: Temas transversais ( $5^{a}$ a $8^{a}$ série) do ensino fundamental. Brasília: MEC/SEF, 1998. $463 p$.

CARVALHO, Isabel Cristina de Moura. Educação ambiental e Movimentos Sociais: elementos para uma história política do campo ambiental. Revista Educação: Teoria e prática. v. 9, n.16, jan./jun. 2001.

Educação Ambiental: pesquisa e desafios. Porto Alegre: Artmed, 2005.

FREIRE, Ana Maria Araújo. O Legado de Paulo Freire à Educação Ambiental. In: NOAL, Fernando Oliveira; BARCELOS, Valdo Hermes de Lima (Orgs). Educação Ambiental e Revbea, Rio Grande, 6: 52-61, 2011. 
Cidadania: Cenários Brasileiros. Santa Cruz do Sul, RS: EDUNISC, 2003.

FREIRE, P. Comunicação e Extensão, Rio de Janeiro: Paz e Terra. 1980.

Educação e Mudança. Rio de Janeiro: Paz e terra, 1984.

Pedagogia do Oprimido. Rio de Janeiro: Paz e terra, 1987.

MORAES, Maria Cândida. O paradigma educacional emergente. Campinas, SP: Papirus, 2003.

MORIN, Edgar. Introdução ao pensamento complexo. Rio de Janeiro: Bertrand Brasil, 1993.

MORIN, Edgar; LE MOIGNE, Jean-Louis. A inteligência da complexidade. São Paulo: Petrópolis, 2000.

MORIN, Edgar. A cabeça bem feita. Repensar a reforma. Reformar o pensamento. Rio de Janeiro: Bertrand Brasil, 2002.

MOSCOVI, Serge. A representação social da psicanálise. Rio de Janeiro: Zahar ,1978. RJ: Vozes, 2007.

Representações Sociais: investigação em psicologia social. 5. ed. Petrópolis,

REIGOTA, M. Meio Ambiente e Representação Social. São Paulo: Cortez, 1998.

. Meio Ambiente e Representação Social. 4. ed. São Paulo: Cortez, 2001.

TRISTÃO, M. Saberes e fazeres da educação ambiental no cotidiano escolar. Revista Brasileira de educação Ambiental, Brasília, Número zero, 2004. 